\title{
The Stanford
}

\section{Nuclear Age Series}

Conceived by scientists, delivered by the military, and adopted by policymakers, nuclear weapons emerged from the ashes of Hiroshima and Nagasaki to dominate our time. The politics, diplomacy, economy, and culture of the Cold War nurtured the nuclear arms race and, in turn, have been altered by it. "We have had the bomb on our minds since 1945," E. L. Doctorow observes. "It was first our weaponry and then our diplomacy, and now it's our economy. How can we suppose that something so monstrously powerful would not, after forty years, compose our identity? The great golem we have made against our enemies is our culture, our bomb culture-its logic, its faith, its vision."

The pervasive, transformative potential of nuclear weapons was foreseen by their creators. When Secretary of War Henry L. Stimson assembled a committee in May 1945 to discuss postwar atomic energy planning, he spoke of the atomic bomb as a "revolutionary change in the relations of man to the universe." Believing that it could mean "the doom of civilization," he warned President Truman that this weapon "has placed a certain moral responsibility upon us which we cannot shirk without very serious responsibility for any disaster to civilization."

In the decades since World War II that responsibility has weighed heavily on American civilization. Whether or not we have met it is a matter of heated debate. But that we must meet it, and, moreover, that we must also prepare the next generation of leaders to meet it as well, is beyond question.

Today, over half a century into the nuclear age the pervasive impact of the nuclear arms race has stimulated a fundamental reevaluation of the role of nuclear armaments and strategic polices. But mainstream scholarly work in 
strategic studies has tended to focus on questions related to the development, the deployment, and the diplomacy of nuclear arsenals. Such an exclusively managerial focus cannot probe the universal revolutionary changes about which Stimson spoke, and the need to address these changes is urgent. If the academic community is to contribute imaginatively and helpfully to the increasingly complex problems of the nuclear age, then the base of scholarship and pedagogy in the national security-arms control field must be broadened. It is this goal that the Stanford Nuclear Age Series is intended to support, with paperback reissues of important out-of-print works and original publication of new scholarship in the humanities and social sciences.

Martin J. Sherwin

General Editor 